\title{
Spatiotemporal Variation of Flash Floods in the Hengduan Mountains Region Affected by Rainfall Properties and Land-use
}

\section{Xiaoyun Sun}

Institute of Geographic Sciences and Natural Resources Research CAS: Institute of Geographic Sciences and Natural Resources Research Chinese Academy of Sciences

\section{Guotao Zhang}

Institute of Mountain Hazards and Environment Chinese Academy of Sciences

Jiao Wang ( $\nabla$ wangjiao@imde.ac.cn )

Institute of Mountain Hazards and Environment Chinese Academy of Sciences

\section{Chaoyue Li}

Institute of Geographic Sciences and Natural Resources Research CAS: Institute of Geographic Sciences and Natural Resources Research Chinese Academy of Sciences

\section{Shengnan Wu}

Institute of Geographic Sciences and Natural Resources Research CAS: Institute of Geographic Sciences and Natural Resources Research Chinese Academy of Sciences

Yao Li

Institute of Mountain Hazards and Environment Chinese Academy of Sciences

\section{Research Article}

Keywords: Flash floods, Spatiotemporal variation, Rainfall, Land-use, The Hengduan Mountains region

Posted Date: June 4th, 2021

DOl: https://doi.org/10.21203/rs.3.rs-561906/v1

License: (c) (i) This work is licensed under a Creative Commons Attribution 4.0 International License. Read Full License

Version of Record: A version of this preprint was published at Natural Hazards on October 30th, 2021. See the published version at https://doi.org/10.1007/s11069-021-05061-5. 


\section{Spatiotemporal variation of flash floods in the Hengduan Mountains} region affected by rainfall properties and land-use

Xiaoyun Sun ${ }^{1,4}$, Guotao Zhang ${ }^{2,4}$, Jiao Wang ${ }^{2,3, *}$, Chaoyue $\mathrm{Li}^{1,4}$, Shengnan $\mathrm{Wu}^{1,4}$, Yao $\mathrm{Li}^{1,4}$

Abstract: Understanding the spatiotemporal characteristic of flash floods is significant for the reasonable and accurate identification of high-risk regions of disasters as well as future prediction of hydrological regimes. Therefore, this study collected time-series datasets (1979-2015) of historical flash flood events, rainfall, and land-use in the Hengduan Mountains region, China to characterize the spatiotemporal variation in flash floods affected by the change in rainfall and land-use. Using linear trend, a significant increase with 12 times/10a for flash flood events was found while $82 \%$ of events occurred in the flood season (June-August). They were closely related to the increase in frequency $(3.5 \mathrm{~d} / 10 \mathrm{a})$ and magnitude $(215.55$ $4 \mathrm{~mm} / 10 \mathrm{a})$ of heavy rainfall as well as the amplified artificial $\left(999 \mathrm{~km}^{2}\right)$. Affected by heavy rainfall due to climate change and human activity, significant periodic

\footnotetext{
* Jiao Wang wangjiao@imde.ac.cn

${ }^{1}$ Key Laboratory of Land Surface Pattern and Simulation, Institute of Geographic Sciences and Natural Resources Research, Chinese Academy of Sciences, Beijing 100101, China

${ }^{2}$ Key Laboratory of Mountain Hazards and Surface Process, Institute of Mountain Hazards and Environment, Chinese Academy of Sciences (CAS), Chengdu 610041, China

${ }^{3}$ China-Pakistan Joint Research Center on Earth Sciences, CAS-HEC, Islamabad 45320, Pakistan.

${ }^{4}$ University of Chinese Academy of Sciences, Beijing 100049, China
} 
variations on the scales of 3-7a, 8-15a, and 21-31a were derived based on the Morlet wavelet analysis. Meanwhile, utilizing the standard elliptical difference, we identified the moving route of the gravity center of flash floods, with the direction from northwest to southeast. More recorded disasters generally were found in the south of the Hengduan Mountain region, where was mainly controlled by frequent rainstorms and the formation of more cropland and artificial with higher runoff potential. These findings can be an appropriate supplement for lack of understanding of the spatiotemporal dynamics of flash floods in the Hengduan Mountains region and could provide policymakers with evidence to identify high-risk areas which is difficult to cope with in the mountainous watershed.

Keywords: Flash floods; Spatiotemporal variation; Rainfall; Land-use; The Hengduan Mountains region

\section{HIGHLIGHTS}

- Spatiotemporal variation of flash flood events (FFE) in the Hengduan Mountains region (HMR) is characterized based on the recorded 1979-2015 events datasets.

- A significant increase with 12 times/10a for FFE is found due to heavy rainfall and the amplified artificial related to climate change and human activity.

- Significant periodic variations on the scales of $3-7 \mathrm{a}$, and $8-15 \mathrm{a}$ for FFE are derived.

- The high-risk regions of flash flood disasters were identified in the south of the HMR. 


\section{Introduction}

Flash floods, one of the deadliest natural hazards worldwide (Špitalar et al., 2014), generally result in loss of life and substantial economic damage (Kumar et al., 2018; Saharia et al., 2017; Yu et al., 2018b). Despite the global scale of flash floods happened, the suffering caused by flash floods remains unevenly distributed between different regions. For example, Asia and the Pacific are most afflicted compared to any other area of the world, account for over $90 \%$ of global disasters and upward trends of flash flood occurrences and impacts (Atif et al., 2021; Kimuli et al., 2021; Singh and Kumar, 2013). China, a mountainous country covering $2 / 3$ of its area, is most threatened by flash floods with more than 60000 events during 1949-2015(Yuan et al., 2017). The frequency and mortality of flash floods are the largest in Asia (Hu et al., 2018), and present a significant spatiotemporal disparity due to the complex monsoon climate and diverse geomorphological types (He et al., 2017; Liu et al., 2018; Liu et al., 2017).

Land-use and climate change are often referred to as 'global change' (Lopez-Tarazon et al., 2019), are two of the most critical drivers of hydrological variations (Kim et al., 2013; Kundu et al., 2017), affecting the formation and development of flash floods due to a complex interaction of the water-vegetation-soil system (Swain et al., 2021; Wang et al., 2020; Zhang et al., 2018). The weather system is becoming more and more unstable under climate change, increasing extreme weather events (Roy et al., 2020; Yu et al., 2018a). One of the main impacts appears to increase the frequency and 
magnitude of extreme rainfall events (Allan and Soden, 2008; Barredo, 2006; Debortoli et al., 2017; Li et al., 2021; Llasat et al., 2021). Meanwhile, Land-use has undergone tremendous transition due to urbanization and the intensification of human activities (Antonio et al., 2019; Avashia and Garg, 2020; Wan Mohtar et al., 2020). Flash floods susceptibility in many regions is particularly heightened due to changing frequencies and magnitudes of extreme rainfall or land-use changes, particularly affected by a large urban growth (Borga et al., 2010; Llasat et al., 2016; Penna and Borga, 2013). Therefore, the increase in flash floods caused by the change in rainfall and land-use has attracted worldwide attention. It was quantitatively assessed that the impact of climate and land-use changes on the streamflow variations (Bronstert et al., 2002; Shahid et al., 2017; Swain et al., 2021), the discharges of the watershed with size from10 $\mathrm{km}^{2}$ to $201 \mathrm{~km}^{2}$ increased $185-560 \mathrm{~m} / \mathrm{s}^{3}$ from the baseline land-use to the urbanized in the Mediterranean by Antonio et al. (Antonio et al., 2019). And it was demonstrasted that a increasing trend of flash floods due to the rainfall and land-use variation (Llasat et al., 2014; Zhang et al., 2019b), the risk of flash floods in the Yesanpo Scenic Area of, Beijing, China, which has increased by $28 \%$ due to the development of tourism and land-use change (Chen et al., 2020).

As a 'natural laboratory' of climate change in China and even the world, the Tibetan Plateau is very sensitive to climate change (Cui et al., 2014; Cui et al., 2015; Yang et al., 2020). The Hengduan Mountains region (HMR), located in the eastern margin of the Tibetan Plateau, also has an obvious response to climate change (Wang et al., 2013; Xu et al., 2018), with an increase in extreme precipitation (Huang et al., 2020; Shi et al., 
2014; Wu et al., 2017; Zhang et al., 2014). Heavy rainfall distribution was affected by the complex topography and presented a significant spatial discrepancy (Li et al., 2021; Li et al., 2011; Ma et al., 2013). The morphology of the mountainous basins with small and steep river catchments can turn the intense runoff generation into severe devastating flash floods (Penna and Borga, 2013). Besides, the HMR has experienced dramatic land-use alterations over the past 20 years (Wang et al., 2018), but the effects of these changes on flash floods remain small. Additionally, the active strong earthquakes, frequent extreme rainfall events, and intensive artificial of major projects (such as the Sichuan-Tibet Railway) in the HMR severely affect the drastic hydrological changes in the Mountainous area, possibly leading to the increasing of the risk of flash floods (Zhang et al., 2021a; Zhang et al., 2019a).

It is essential to conduct comprehensive documentation of past events for flash flood research (Wang et al., 2020). Many researchers have been shown to collect history flash flood events and create the events database (Gaume et al., 2009), and being intensively studies of using the events, thus investigating frequency, temporal evolution, spatial distribution and patterns, fatalities, and injuries, as well as the seasonality of flash floods (Kaiser et al., 2021; Llasat et al., 2014), and analyzing the influence of environmental factors on the distribution of flash floods (Wang et al., 2020; Xiong et al., 2019). Also, the models were used to predict flash floods in the future (Avashia and Garg, 2020; Zhang et al., 2021b). However, there was a lack of synchronous analysis of the long-term spatiotemporal evolution of flash floods with rainfall and land-use due to the constraints of recorded data. 

(1979-2015) of historical flash flood events, rainfall, and land-use. The objectives of on the spatiotemporal characteristics of flash floods. They could provide scientific reference and decision-making for formulating reasonable measures of disaster prevention and mitigation, as well as effective flood risk management.

\section{Materials and Methods}

\subsection{Study area}


The significant difference in climate conditions between different regions contributes to various vegetation types (Yin et al., 2020), including shrub, forest, and meadows.

Fig. 1 The HMR with meteorological stations and locations of flash flood events

\subsection{Data preparation}

\subsubsection{Flash flood events}

The flash flood events data are mainly from the database of the "National Flash Flood Investigation and Evaluation Project" of China Institute of Water Resources and Hydropower Research, including the records of more than 60,000 flash flood events of China from 1950 to 2015, as well as the occurrence time, location, precipitation and injuries of the disaster events. In consideration of incomplete records in the early period, the data of 2044 flash flood events in the HMR from 1979 to 2015 were selected in this study.

\subsubsection{Rainfall}

Daily precipitation data, including meteorological station data and grid data, were used to analyze the spatiotemporal evolution of rainfall in the HMR. The meteorological station data were acquired by national standard meteorological stations in the HMR, and 25 stations were selected based on their record length with flash floods data - the data obtained from the China Meteorological Data Network (http://data.cma.cn). The grid data is CPC Global Unified Gauge-Based Analysis of Daily Precipitation ( 0.50 - degree latitude $\times 0.50$ - degree longitude grid ), which is part of products suite from the Unified Precipitation Project that is underway at the National Oceanic and Atmospheric Administration (NOAA) Climate Prediction 
Center (CPC), available from https://psl.noaa.gov/.

Rainfall events are often classified in terms of depth of rain deliver in 24 hours (Breugem et al., 2020), in this respect, mentions heavy rainfall defined as daily precipitation greater than or equal to $50 \mathrm{~mm}$, and the rainstorm days is the number of days in which a heavy rainfall event occurs. This indicator is not only a "climate change indices" (http://etccdi.pacificclimate.org/list_27_indices.shtml) used by the World Meteorological Organization Climate Commission for Climatology (WMO-CCI), and widely used rainstorm classification standard in China (Li et al., 2019; Zhang et al., 2014; Zhou et al., 2011). At the same time, this threshold is also the critical value for the warning of mountain disasters in the region (Li et al., 2019).

\subsubsection{Land-use}

This study used land-use data (1 km resolution) from Resource and Environment Science and Data Center of Chinese Academy of Sciences (http://www.resdc.cn/), which provides land-use data at 5-year or 10-year intervals from 1980 to 2015 in six classes: cropland, forest, grass, water, artificial, and unused land.

\subsection{Methods}

\subsubsection{Linear trend and Wavelet analysis}

The changing trend of flash floods and rainfall is expressed by a linear equation (Mudelsee, 2019; Xu et al., 2018), that is:

$$
y=a+b t
$$

where $y$ is flash flood events and rainfall, $t$ is time ( the time is 1979-2015 in this study ), $b$ is the linear trend term. 

processing and has been widely used in the time-frequency analysis of rainfall series. Morlet wavelet function is a kind of complex-valued wavelet that is widely used for systematic analysis. Its expression is as follows:

$$
\varphi(t)=e^{i c t} \mathfrak{g}^{-t^{2} / 2}
$$

where $i$ is a complex, $c$ is a constant.

For a given discrete time series $f(k \Delta t)(k=1,2, \mathrm{~K}, N ; \Delta t$ is the sampling interval ), and its wavelet transform is

$$
W_{f}(a, b)=|a|^{-1 / 2} \sum_{k=1}^{N} f(k) \mathfrak{g}^{i c t} e^{-t^{2} / 2}
$$

where $a$ is the period length of the wavelet; $b$ is the time shift of the wavelet; $W_{f}(a, b)$ is the wavelet transform coefficient.

On this basis, the wavelet square difference is calculated, namely:

$$
\operatorname{var}=\int_{-\infty}^{\infty}\left|W_{f}(a, b)\right|^{2} d b
$$

equation (3) is used to calculate the wavelet variance and draw the wavelet variance graph, the main period of time-series can be determined.

\subsubsection{Gravity center model and standard deviation ellipse}

The gravity center (mean center) was used to systematically analyze the historical flash flood events and rainfall in the HMR from 1979 to 2015. According to the moving track and distance of disasters center in ten years, the directional distribution of disasters was analyzed in combination with the standard deviation ellipse (Xiong et al., 2019). The standard deviational ellipse is used to identify the spatial distribution of historical flash flood events and to represent the location change 
and movement trend of disasters center. The long axis of the standard deviational ellipse represents the directivity of the spatial distribution of flash floods. In contrast, the short axis represents the dispersion degree of the spatial distribution of the disasters.

The mean center is the average $x$ - and $y$-coordinate of all the features in the study area. It's helpful in tracking changes in the distribution or for comparing the distributions of different types of components. The mean center is given as:

$$
\bar{X}=\frac{\sum_{i=1}^{n} x_{i}}{n}, \bar{Y}=\frac{\sum_{i=1}^{n} y_{i}}{n}
$$

where $x_{i}$ and $y_{i}$ are the coordinates for feature $i$, and $n$ is equal to the total number of features.

The weighted mean center extends to the following:

$$
\overline{X_{w}}=\frac{\sum_{i=1}^{n} w_{i} x_{i}}{\sum_{i=1}^{n} w_{i}}, \overline{Y_{w}}=\frac{\sum_{i=1}^{n} w_{i} y_{i}}{\sum_{i=1}^{n} w_{i}}
$$

where $w_{i}$ is the weight at feature $i$.

The standard deviational ellipse is used to identify the spatial distribution of historical flash floods and to represent the location change and movement trend of disasters center. The long axis of the standard deviational ellipse represents the directivity of the spatial distribution of disasters. In contrast, the short axis represents the dispersion degree of the spatial distribution of catastrophe.

The Standard Deviational Ellipse is given as: 


$$
S E D_{x}=\sqrt{\frac{\sum_{i=1}^{n}\left(x_{i}-\bar{X}\right)^{2}}{n}}, S E D_{y}=\sqrt{\frac{\sum_{i=1}^{n}\left(y_{i}-\bar{Y}\right)^{2}}{n}}
$$

214 where $x_{i}$ and $y_{i}$ are the coordinates for feature $i,\{\bar{X}, \bar{Y}\}$ represent the mean center for

215 features, and $n$ is equal to the total number of the features.

The angle of rotation is calculated as:

$$
\tan \theta=\frac{A+B}{C}
$$

221 where $\tilde{x}_{i}$ and $\tilde{y}_{i}$ are the deviations of the $x y$-coordinates from the mean center.

\section{Results}

\subsection{Temporal variation in flash floods}

The interannual variability of flash floods in the HMR during 1979-2015 was analyzed with the undulant rising characteristic at 12 times/10a (Fig. 2a). There were two particular large flash flood events exceptions in 1991 (138 events) and 1998 (230 events) when the catastrophic floods were triggered by the monsoon rainfalls in the Yangtze River Basin, resulting in 4150 people died and directed economic losses of RMB166 billion (Kundzewicz et al., 2020). Meanwhile, it was found that the monthly distribution of flash floods mainly occurred in summer from June to August, with the occupy $82.0 \%$ (1594 events) of the whole year (Fig. 2b). The largest proportion 
appeared in July with 670 occurrences, accounting for $34.8 \%$ of the total. This finding has been verified each year from 1979 to 2015, indicating the frequent month of flash flood disaster occurrence.

Fig. 2 The statistically annual variation (a) and monthly distribution (b) of flash floods in the HMR during 1979-2015

Additionally, the periodic changes of the time-series flash floods were identified based on the wavelet coefficients (Fig.3a), which could be used to predict the future change trend of the flash floods at different time scales. It can be seen that the potential periodicities with 3-7a, 8-15a, and 21-31a of the time-series flash floods from 1979 to 2015 (Fig. 3a) were obtained, and significant periodicity with the local higher energy density appeared in the periods of $3-7 \mathrm{a}$ and $8-15 \mathrm{a}$. But the period of 21-31a with the weak energy was widely distributed in the periods from 1979 to 2015 . Three prominent peaks were found in the wavelet deviation diagram (Fig. 3b), The fluctuation of three periods efficiently controlled the variation characteristics of flash appeared in the period scale of 9 a when indicating the strongest periodic oscillation.

Fig.3 Distribution of time frequencies on the real part of wavelet transform (a) and interval. In different decades, the spatial moving track and distance of gravity center of flash floods were analyzed based on the gravity center model (Fig. 4), and the 
disaster distribution and direction were comprehensively estimated using the standard deviation ellipse. The calculated critical parameters of gravity center and standard deviation elliptical were determined in Table.1, including coordinate and the movement distance of centroids, as well as direction angle and $\mathrm{X}, \mathrm{Y}$-axis distance of standard deviation elliptical. During the periods from 1979 to 2015, the region in the gravity center of flash floods was determined between $101.40^{\circ} \sim 101.59^{\circ} \mathrm{E}$, $26.99^{\circ} \sim 28.03^{\circ} \mathrm{N}$, located in Panzhihua City and Liangshan Yi Autonomous Prefecture, Sichuan province.

It was found that the gravity center mainly moved upward from northeast to southeast, first moving $74 \mathrm{~km}$ from north to south, then $3 \mathrm{~km}$ west, and finally $174 \mathrm{~km}$ northeast; The change of the direction angle was not significant, ranging from $3.44^{\circ}$ to $174.13^{\circ}$. The flash floods presented a north-south pattern, and the pattern showed a trend of strengthening, strengthening, and weakening in turn. The length of the significant half axis along the $\mathrm{X}$-axis showed a decreasing trend on the whole, and the data showed a high-low-high fluctuation, indicating that the directivity of the spatial distribution of flash floods first weakened and then increased. The north-south pattern changed from significant to non-significant and then to substantial. The average length of the short half axis along the Y-axis was $264 \mathrm{~km}$. The short half axis of 1979-1985 was the longest, indicating that the centripetal force of the distribution of flash floods was weak and the dispersion degree of disasters was large.

Fig.4 Gravity Center and Directional Distribution of flash floods from 1979 to 2015

Table 1 The parameters of gravity center and standard deviation ellipse in different 
decades from 1979 to 2015

\subsection{Changes in rainfall characteristics and land-use}

\subsubsection{Rainfall characteristic}

A decreasing trend of $10.48 \mathrm{~mm} / 10 \mathrm{a}$ for the average annual rainfall was found in the HMR, and the maximum value of precipitation appeared in 1998 (Fig. 5a). However, an increasing trend of $3.5 \mathrm{~d} / 10 \mathrm{a}$ for the number of rainstorm days and $255.6 \mathrm{~mm} / 10 \mathrm{a}$ for rainstorms precipitation was determined, and the peaks also occurred in 1998 (Fig. 5b, c). Additionally, the monthly rainfall depth and the number of rainstorm days varied significantly within the year, and both maximum values occurred in July (Fig. 5d). Especially, the rainstorm days and rainstorms precipitation from June to August accounted for $80 \%$ of the total of each year (Fig. 5e, f). The characteristic was parallel to the temporal variations in flash flood events. The annual distribution of precipitation shows clear seasonality, being strongly influenced by the monsoon.

Fig. 5 Annual evolution (a, b, c) and monthly distribution (d, e, f) of the rainfall (unit: $\mathrm{mm}$ ), the rainstorm days (unit: d), and the rainstorms precipitation (unit: $\mathrm{mm}$ ) in the HMR from 1979 to 2015

Three over-centers (i.e. 1886, 2006, 2014) and two under-centers (1979 and 2015) were obtained during the periods from 1979 to 2015 . It can be seen from Fig.6a that during the evolution process of rainfall from 1979 to 2015, there was a certain periodicity on the scales of 3-8a, 9-17a, and 21-32a. In contrast, the energy density of 21-32a was relatively high, but the periodic variation was only significant from 1989 
to 2011 , while the other periodic time-domain was fairly broad but not significant. In

299 the wavelet square deviation graph (Fig. 6b), there were two fairly obvious peaks,

300 which correspond to the time scale of $22 \mathrm{a}$ and $28 \mathrm{a}$ successively from small to large.

301 The maximum peak corresponds to the time scale of $28 \mathrm{a}$, indicating that the periodic

302 oscillation of about 28a was the strongest, which was the first main period of rainfall

303 variation. The 22a time scale corresponds to the second peak, which is the second

304 principal period.

305 Fig. 6 Distribution of time frequencies on the real part of wavelet transform (a) and

306 the wavelet variances (b) in precipitations in the HMR during 1979-2015

The spatial distribution of rainfall in the HMR region was different, affected by

308 the topography (Li et al., 2021), which decreased from southwest to northwest (Fig.

309 7a-d). The rainy belt was in a 'NE-SW' direction, and the rainfall center moved in the

310 same order with a distance of 3.8-16.2 km during 1979-2015 (Fig. 7e). The maximum

311 precipitation occurred in the east-north-east direction of the study area, located in

312 Ya'an, Sichuan, a rainstorm center in Sichuan. The minimum of rain appears in the

313 west-north-west order of the study area, situated in Qamdo, Tibet. It is found that

314 heavy rainfall mainly occurs in areas with high precipitation, located in the lower

315 elevation of the south of the region where flash floods frequently occurred (Fig. 8).

316 Fig. 7 Moving track of the rainfall center (1979-2015)

317 Fig. 8 Distribution of the rainstorm days and rainstorm precipitation in 318 meteorological stations in the HMR (1979-2015)

\subsubsection{Land-use change}


The land-use maps in 1980-2015 were shown in Fig. 9, and the area of the

land-use in the different year was counted in Table. 2. It was evident that an apparent spatial heterogeneity in land-use distribution. Forest and grass were the main land-use types and were widely distributed in the mountainous, accounting for about $88 \%$. The grass was mainly concentrated in the north of the region with high altitude, while forests in the middle and south with a low height. Other land-use types were scattered and small in area (only $0.2 \%-7.7 \%$ ). Artificial and cropland are mainly distributed in the southeast of the mountains with lower elevation and concentrated in the river valley due to the topography restriction. Unused land is distributed primarily in the northwest of the region, which is primarily in Ganzi and Qamdo, while the water area is primarily distributed in the middle.

From 1980 to 2015, following the urban development, the artificial expanded rapidly (from $727 \mathrm{~km}^{2}$ to $1726 \mathrm{~km}^{2}$ ), increasing to $137 \%$. Before 2005 , rampant growth led to a significant reduction in forest and increased grass. Then in 2015, the forest has recovered, increasing by $6685 \mathrm{~km}^{2}$ compare with 1980, while grass decreased by $2932 \mathrm{~km}^{2}$. Besides, cropland, water area, and unused land decreased by $138 \mathrm{~km}^{2}, 2284 \mathrm{~km}^{2}$, and $927 \mathrm{~km}^{2}$ respectively in the past 35 years.

Fig. 9 The land-use maps in the HMR from 1980 to $2015\left(\mathrm{~km}^{2}\right)$

Table 2 The area of land-use in the HMR during 1980-2015 $\left(\mathrm{km}^{2}\right)$

The land-use maps of 1980 and 2015 were superimposed to obtain the transfer area matrix, which was shown in Table.3. The land-use changed abruptly and dramatically over the past 35 years in the HMR (Fig.10); in particular, more 
incredible conversion among cropland, forest, the grass is noteworthy. The decrease in cropland is due to conversion to artificial, forest, and grass. The main reason for the decline of grass and the increase of forest is that a large area of grass $\left(49291 \mathrm{~km}^{2}\right)$ has been converted into the forest. These changes were closely related to national policies to protect the ecological environment, such as returning cropland to forest and grass and afforestation. Also, unused land has been turned into grass $\left(1557 \mathrm{~km}^{2}\right)$ and forest $\left(6957 \mathrm{~km}^{2}\right)$, which shows that the ecology of the HMR has been improved. The increase of artificial mainly comes from the conversion of cropland $\left(910 \mathrm{~km}^{2}\right)$ and grass $\left(381 \mathrm{~km}^{2}\right)$. Due to the acceleration of urbanization driven by social and economic development, other land-use types are also being transformed into artificial. The conversion of land-use type to cropland and artificial is mainly in the south of the region, where the altitude is low and human activities are intense, while the conversion to forest and grass is primarily in the northern, especially in the northwest, which is primarily in the high-altitude mountainous areas.

Table 3 Land-use transfer matrix from 1980 to $2015\left(\mathrm{~km}^{2}\right)$

Fig. 10 Distribution of land-use transfer from 1980 to 2015

\section{Discussion}

\subsection{Controls of rainfall properties to spatiotemporal variability in flash floods}

The occurrence and distribution of flash floods are controlled by rainfall, which is the main trigger factor, and associated with short, high-intensity rain (Borga et al., 2010). The heavy rainfall over a short period causes quick-rising flash floods, which is very common (Roy et al., 2020). The contribution of convective precipitation was about 
$50 \%$ for $75 \%$ of the flash floods, and it increases to $70 \%$ for $50 \%$ of them (Llasat et al.,

2016). The HMR is one of the most affected regions, where convective activity bearing severe weather and intense rainfall is favored due to the combination of the multiple monsoons and the complex and accompanied by large spatial and decadal variability (Yin et al., 2018). Flash floods directly linked to rainfall, this study indirectly analyzed whether the magnitude of the trigger itself had also varied through space and time, enabling considerations in the context of climatic changes. It was demonstrated that the spatiotemporal variations of flash floods and triggering factor rainfall are highly consistent.

The annual distribution of rainfall shows clear seasonality, being strongly influenced by the monsoon (Wang et al., 2020; Yuan et al., 2017), mainly concentrated in summer (June to August), and flash floods were highly similar to heavy rainfall because the other factors of flash floods have slight annual variation. There was a decrease in the precipitation $(10.48 \mathrm{~mm} / 10 \mathrm{a})$, but an increase in days $(3.5 \mathrm{~d} / 10 \mathrm{a})$ and precipitation $(215.55 \mathrm{~mm} / 10 \mathrm{a})$ of heavy rainfall events under climate change. The increasing trend of flash floods (12times/10a) was more dramatic than the rainstorms, which may be due to the synergistic effect of the increase in frequency and magnitude of rainstorms (Fig. 11), triggering more flash floods in a rainstorm event. It may also be affected by land-use changes that increase flash flood sensitivity. In addition, it is worth noting that the relationship between flash floods period and rainfall period has been found in this study. The resonance period on the same scales of 3-7a, 21-31a appears in the evolution of flash floods and rainfall during the time series of 
1979-2015, and they were controlled by the same period with $22 \mathrm{a}$.

Fig. 11 Number of flash floods under different rainfall grades consistency with regional topographical changes (del Moral et al., 2020; Li et al., 2021). The spatial distribution of flash floods is more in the south and less in the north, and the least in the northwest, which was similar to the spatial distribution of rainfall and rainstorms. Comparison of gravity center migration trajectory of rainfall and flash floods, the results show that, from 1979-1985 to 1986-1995, the gravity centers of rainfall and flash floods do not overlap. Still, there was a remarkable correlation between the migration trajectory of the gravity center of precipitation and flash floods

\subsection{Effects of land-use on the spatiotemporal characteristic in flash floods}


Land-use change directly impacts the underlying surface of the drainage basin, generally altered the runoff generation and confluence processes at hillslopes (Elfert and Bormann, 2010), furtherly affecting the formation and development of flash floods in the watershed. It was demonstrated that the sensitivity of flash floods increased in artificial and cropland while decreased in forests and grass (Yue et al., 2016).

Forest and grass could intercept rainfall and regulate runoff, efficiently lowering

the peak discharge and delay the peak time of flash floods. In contrast, the frequency of flash floods was higher in artificial and cropland (He et al., 2005; Yue et al., 2016). For example, in the Chabagou catchment with $205 \mathrm{~km}^{2}$, Shaanxi Province, China, the grass and forest could decrease flood peaks by $36 \%$ and $64 \%$, respectively (Fu et al., 2020). In the middle and northwestern of the HMR, large land-use areas have been converted to forest and grass, which can effectively alleviate flash floods, so flash floods were less frequent in this region (Fig. 10). However, due to the destruction of vegetation-soil at cropland and irrigation, can moisten the soil, thus contributing to both precipitation and runoff intensification, it is very extreme to cause flash floods accompanied by soil erosion (Fu et al., 2020; O'Donnell et al., 2011). The small area of cropland only accounts for $7.7 \%, 31.9 \%$ of flash floods occurred in the HMR. High surface runoff from heavy rainfall due to the impervious surfaces and high building densities of artificial, the hydrological response changed to higher flow rate peaks and shorter concentration times, escalate the urban flooding (Antonio et al., 2019; Wan Mohtar et al., 2020). Chen analyzed the risk of flash floods in the Yesanpo Scenic Area of Beijing, China, which has increased by $28 \%$ due to tourism and land-use alteration 
(Chen et al., 2020). The smallest area of artificial could trigger the largest probability of flash floods, accounting for only $0.8 \%$ of the mountain area, but $4.9 \%$ of flash floods occurred. In the south of the HMR, with low altitude and intense human activities, most of the cropland and artificial was distributed. A large of land-use has been altered into them, which is a susceptible area of flash floods. This indicates the effect of the pattern of land-use change on the spatiotemporal evolution of flash floods in the HMR.

\section{Conclusions}

The spatiotemporal variation in flash floods with 2044 events during 1979-2015 in the HMR with high relief were characterized based on linear trend, wavelet analysis, gravity center model, and standard deviational ellipse. A significant increase with 12 times/10a for flash flood events during the periods was found due to the high frequency and magnitude of heavy rainfall and the amplified artificial. It was noted that historical events were characterized by significant periodicities $(3-7 \mathrm{a}, 8-15 \mathrm{a}$, and 21-31a), which were subject to changes in rainstorm extremes affected by climate change and human activity.

Meanwhile, affected by the spatial distribution of heavy rainfall as well as expansion of cropland and artificial, the spatial gravity center of flash floods, during 1979-2015, gradually migrates along the direction from northwest to southeast. Higher frequencies of flash flood events generally appeared in the south region of the HMR, indicating the uneven spatiotemporal distribution of flash flood events. These findings could provide governments' policymakers with reasonable identification and 
future prediction of high-risk regions of the considerable flash floods in the HMR under the future global change scenarios.

\section{Declaration of competing interest}

The authors declare that they have no known competing financial interests or personal relationships that could have appeared to influence the work reported in this paper.

\section{Acknowledgments}

This work was jointly supported by the Major Program of National Natural Science Foundation of China (Grant numbers 41790432 and 41941017); the Strategic Priority Research Program of the Chinese Academy of Sciences (Grant number XDA23090303).

\section{Author contributions}

Xiaoyun Sun: Conceptualization, Methodology, Software, Writing. Guotao Zhang: Conceptualization, Supervision, Writing - review \& editing. Jiao Wang: Supervision, Funding acquisition. Chaoyue Li: Conceptualization, Software.

Shengnan Wu: Writing - review \& editing. Yao Li: Methodology, Software.

Declaration of interests

$\bigotimes$ The authors declare that they have no known competing financial interests or personal relationships that could have appeared to influence the work reported in this paper.

$\square$ The authors declare the following financial interests/personal relationships which may be considered as potential competing interests: 


\section{References}

480

481

Allan RP and Soden BJ (2008) Atmospheric warming and the amplification of precipitation $\quad$ extremes. $\quad$ Science, $\quad 321(5895)$ : 1481-1484. http://dx.doi.org/10.1126/science.1160787

Antonio JA, Javier VA, Pla C et al. (2019) Impact of land use changes on flash flood prediction using a sub-daily SWAT model in five Mediterranean ungauged watersheds (SE Spain). Sci Total Environ, 657: 1578-1591. http://dx.doi.org/10.1016/j.scitotenv.2018.12.034

Atif S, Umar M and Ullah F (2021) Investigating the flood damages in Lower Indus Basin since 2000: Spatiotemporal analyses of the major flood events. Natural Hazards. http://dx.doi.org/10.1007/s11069-021-04783-w

Avashia V and Garg A (2020) Implications of land use transitions and climate change on local flooding in urban areas: An assessment of 42 Indian cities. Land Use Policy, 95: 104571. http://dx.doi.org/10.1016/j.landusepol.2020.104571

Barredo JI (2006) Major flood disasters in Europe: 1950-2005. Natural Hazards, 42(1): 125-148. http://dx.doi.org/10.1007/s11069-006-9065-2

Borga M, Anagnostou EN, Blöschl G et al. (2010) Flash floods: Observations and analysis of hydro-meteorological controls. Journal of Hydrology, 394(1-2): 1-3. http://dx.doi.org/10.1016/j.jhydrol.2010.07.048

Breugem AJ, Wesseling JG, Oostindie K et al. (2020) Meteorological aspects of heavy 
precipitation in relation to floods - An overview. Earth-Science Reviews, 204: 103171. http://dx.doi.org/10.1016/j.earscirev.2020.103171

501 Bronstert A, Niehoff D and Bürger G (2002) Effects of climate and land-use change on storm runoff generation: present knowledge and modelling capabilities. Hydrological Processes, 16(2): 509-529. http://dx.doi.org/10.1002/hyp.326

Chen Y, Wang Y, Zhang Y et al. (2020) Flash floods, land-use change, and risk dynamics in mountainous tourist areas: A case study of the Yesanpo Scenic Area, Beijing, China. International Journal of Disaster Risk Reduction, 50: 103171. http://dx.doi.org/https://doi.org/10.1016/j.ijdrr.2020.101873

Cui P, Chen R, Xiang L et al. (2014) Risk Analysis of mountain hazards in Tibetan Plateau under global warming Climate Change Research, 10(2): 103-109.

Cui P, Su F, Zou Q et al. (2015) Risk assessment and disaster reduction strategies for mountainous and meteorological hazards in Tibetan Plateau. Chinese Science Bulletin, 60(32): 3067-3077. http://dx.doi.org/10.1360/n972015-00849

Debortoli NS, Camarinha PIM, Marengo JA et al. (2017) An index of Brazil's vulnerability to expected increases in natural flash flooding and landslide disasters in the context of climate change. Natural Hazards, 86(2): 557-582. http://dx.doi.org/10.1007/s11069-016-2705-2

del Moral A, Llasat MdC and Rigo T (2020) Connecting flash flood events with radar-derived convective storm characteristics on the northwestern Mediterranean coast: knowing the present for better future scenarios adaptation. Atmospheric Research, 238: 104863. http://dx.doi.org/10.1016/j.atmosres.2020.104863 
Elfert S and Bormann H (2010) Simulated impact of past and possible future land use changes on the hydrological response of the Northern German lowland 'Hunte' $\begin{array}{llll}\text { catchment. Journal of } & \text { Hydrology, 383(3-4): }\end{array}$ http://dx.doi.org/10.1016/j.jhydrol.2009.12.040

Fu S, Yang Y, Liu B et al. (2020) Peak flow rate response to vegetation and terraces under extreme rainstorms. Agriculture, Ecosystems \& Environment, 288: 106714. http://dx.doi.org/10.1016/j.agee.2019.106714

Gaume E, Bain V, Bernardara P et al. (2009) A compilation of data on European flash floods. Journal of Hydrology, 367(1-2): 70-78. http://dx.doi.org/10.1016/j.jhydrol.2008.12.028

He B, Huang X, Ma M et al. (2017) Analysis of flash flood disaster characteristics in China from 2011 to 2015. Natural Hazards, 90(1): 407-420. http://dx.doi.org/10.1007/s11069-017-3052-7

He Y, Ma Z, Xie H et al. (2005) Mountain hazards intergrated senstivity on land use of the upper reaches of Yangtza River--A case study of Xiaojiang River Basin. Resources and Environment in the Yangtze Basin, 14(4): 528-533.

Hu P, Zhang Q, Shi P et al. (2018) Flood-induced mortality across the globe: Spatiotemporal pattern and influencing factors. Sci Total Environ, 643: 171-182. http://dx.doi.org/10.1016/j.scitotenv.2018.06.197

Huang C, Li G, Zhang F et al. (2020) Evolution characteristics of mountain rainstorms over Sichuan Province in the past ten years under the influence of climate change. Torrential Rain and Disasters, 39(4): 335-343. 
Kaiser M, Günnemann S and Disse M (2021) Spatiotemporal analysis of heavy rain-induced flood occurrences in Germany using a novel event database $\begin{array}{llll}\text { approach. Journal of } & \text { Hydrology, }\end{array}$ http://dx.doi.org/10.1016/j.jhydrol.2021.125985

Kim J, Choi J, Choi C et al. (2013) Impacts of changes in climate and land use/land cover under IPCC RCP scenarios on streamflow in the Hoeya River Basin, Korea. Sci Total Environ, 452-453: $181-95$. http://dx.doi.org/10.1016/j.scitotenv.2013.02.005

Kimuli JB, Di B, Zhang R et al. (2021) A Multisource Trend Analysis of Floods in Asia-Pacific 1990 - 2018: Implications for Climate Change in Sustainable Development Goals. International Journal of Disaster Risk Reduction, 59: 102237. http://dx.doi.org/10.1016/j.ijdrr.2021.102237

Kumar A, Gupta AK, Bhambri R et al. (2018) Assessment and review of hydrometeorological aspects for cloudburst and flash flood events in the third pole region (Indian Himalaya). Polar Science, 18: 5-20. http://dx.doi.org/10.1016/j.polar.2018.08.004

Kundu S, Khare D and Mondal A (2017) Individual and combined impacts of future climate and land use changes on the water balance. Ecological Engineering, 105: 42-57. http://dx.doi.org/10.1016/j.ecoleng.2017.04.061

Kundzewicz ZW, Huang J, Pinskwar I et al. (2020) Climate variability and floods in China - A review. Earth-Science Reviews, 211: 103434. 
566

Li G, Yu Z, Wang W et al. (2021) Analysis of the spatial Distribution of precipitation and topography with GPM data in the Tibetan Plateau. Atmospheric Research, 247: 105259. http://dx.doi.org/10.1016/j.atmosres.2020.105259

Li Q, Wang Y, Xu P et al. (2019) Changes of extreme precipitation patterns for disaster prone areas in the north of the Hengduan Mountains under climate change. Mountain Resarch 37(3): 400-408.

Li Z, He Y, Wang C et al. (2011) Spatial and temporal trends of temperature and precipitation during 1960-2008 at the Hengduan Mountains, China. Quaternary International, 236(1-2): 127-142. http://dx.doi.org/10.1016/j.quaint.2010.05.017

Li Z, He Y, Wang P et al. (2012) Changes of daily climate extremes in southwestern China during 1961-2008. Global and Planetary Change, 80-81: 255-272. http://dx.doi.org/10.1016/j.gloplacha.2011.06.008

Liu Y, Yang Z, Huang Y et al. (2018) Spatiotemporal evolution and driving factors of China's flash flood disasters since 1949. Science China Earth Sciences, 61(2): 1804-1817. http://dx.doi.org/10.1360/n072017-00328

Liu Y, Yuan X, Guo L et al. (2017) Driving Force Analysis of the Temporal and Spatial Distribution of Flash Floods in Sichuan Province. Sustainability, 9(9): 1527. http://dx.doi.org/10.3390/su9091527

Llasat MC, del Moral A, Cortès M et al. (2021) Convective precipitation trends in the Spanish Mediterranean region. Atmospheric Research. http://dx.doi.org/10.1016/j.atmosres.2021.105581 
Llasat MC, Marcos R, Llasat-Botija M et al. (2014) Flash flood evolution in North-Western Mediterranean. Atmospheric Research, 149: 230-243. http://dx.doi.org/10.1016/j.atmosres.2014.05.024

Llasat MC, Marcos R, Turco M et al. (2016) Trends in flash flood events versus convective precipitation in the Mediterranean region: The case of Catalonia. Journal of Hydrology, 541: 24-37. http://dx.doi.org/10.1016/j.jhydrol.2016.05.040

Lopez-Tarazon JA, Bronstert A, Thieken AH et al. (2019) The effects of global change on floods, fluvial geomorphology and related hazards in mountainous $\begin{array}{lllll}\text { rivers. } & \text { Sci } & \text { Total } & \text { Environ, } & \text { 669: }\end{array}$ http://dx.doi.org/10.1016/j.scitotenv.2019.03.026

Ma Z, Liu J, Zhang S et al. (2013) Observed Climate Changes in Southwest China during 1961-2010. Advances in Climate Change Research, 4(1): 30-40. http://dx.doi.org/10.3724/sp.J.1248.2013.030

Mudelsee M (2019) Trend analysis of climate time series: A review of methods.

$$
\text { Earth-Science } \quad \text { Reviews, } \quad 190 \text { : }
$$

$$
\text { http://dx.doi.org/10.1016/j.earscirev.2018.12.005 }
$$

O’Donnell G, Ewen J and O'Connell PE (2011) Sensitivity maps for impacts of land management on an extreme flood in the Hodder catchment, UK. Physics and Chemistry of the Earth, Parts A/B/C, 36(13): 630-637. http://dx.doi.org/10.1016/j.pce.2011.06.005

Penna D and Borga M (2013) Natural Hazards Assessment in Mountainous Terrains of Europe, Climate Vulnerability, pp. 229-239. 
Roy P, Chandra Pal S, Chakrabortty R et al. (2020) Threats of climate and land use change on future flood susceptibility. Journal of Cleaner Production, 272: 122757. http://dx.doi.org/10.1016/j.jclepro.2020.122757

Saharia M, Kirstetter P-E, Vergara H et al. (2017) Characterization of floods in the United States. Journal of Hydrology, 548: 524-535. http://dx.doi.org/10.1016/j.jhydrol.2017.03.010

Shahid M, Cong Z and Zhang D (2017) Understanding the impacts of climate change and human activities on streamflow: a case study of the Soan River basin, Pakistan. Theoretical and Applied Climatology, 134(1-2): 205-219. http://dx.doi.org/10.1007/s00704-017-2269-4

Shi P, Sun S, Wang M et al. (2014) Climate change regionalization in China (19612010). Science China Earth Sciences, 44: 2294-2306.

Singh O and Kumar M (2013) Flood events, fatalities and damages in India from 1978 to 2006. Natural Hazards, $\quad$ 69(3): 1815-1834. http://dx.doi.org/10.1007/s11069-013-0781-0

Špitalar M, Gourley JJ, Lutoff C et al. (2014) Analysis of flash flood parameters and human impacts in the US from 2006 to 2012. Journal of Hydrology, 519: 863-870. http://dx.doi.org/10.1016/j.jhydrol.2014.07.004

Swain SS, Mishra A, Chatterjee C et al. (2021) Climate-changed versus land-use altered streamflow: A relative contribution assessment using three complementary approaches at a decadal time-spell. Journal of Hydrology, 596: 126064. http://dx.doi.org/10.1016/j.jhydrol.2021.126064 
631

632

633

634

635

636

637

638

639

640

641

642

643

644

645

646

647

648

649

650

651

652

Teresa PC and Gabriele C (2020) Intra-catchment comparison and classification of long-term streamflow variability in the Alps using wavelet analysis. Journal of Hydrology, 587: 124927. http://dx.doi.org/10.1016/j.jhydrol.2020.124927

Wan Mohtar WHM, Abdullah J, Abdul Maulud KN et al. (2020) Urban flash flood index based on historical rainfall events. Sustainable Cities and Society, 56: 102088. http://dx.doi.org/10.1016/j.scs.2020.102088

Wang N, Lombardo L, Tonini M et al. (2020) Implications of land use transitions and climate change on local flooding in urban areas An assessment of 42 Indian cities. Natural Hazards and Earth System Sciences. http://dx.doi.org/10.5194/nhess-2020-238

Wang S, Jiao S and Xin H (2013) Spatio-temporal characteristics of temperature and precipitation in Sichuan Province, Southwestern China, 1960-2009. Quaternary International, 286: 103-115. http://dx.doi.org/10.1016/j.quaint.2012.04.030

Wang Y, Dai E, Yin L et al. (2018) Land use/land cover change and the effects on ecosystem services in the Hengduan Mountain region, China. Ecosystem Services, 34: 55-67. http://dx.doi.org/10.1016/j.ecoser.2018.09.008

Wu S, Pan T, Liu Y et al. (2017) Comprehensive climate change risk regionalization of China. Acta Geographica Sinica, 72(1): 3-17. http://dx.doi.org/10.11821/dlxb201701001

Xiong J, Li J, Cheng W et al. (2019) Spatial-temporal distribution and the influencing factors of mountain flood disaster in southwest China. Acta Geographica Sinica, 74(7): 1374-1391. http://dx.doi.org/10.11821/dlxb201907008 
653

654

655

656

657

658

659

660

661

662

663

664

665

666

667

668

669

670

671

672

673

674

Xu F, Jia y, Niu C et al. (2018) Variation Character of Annual, Seasonal and Monthly Temperature and Precipitation. Mountain Resarch, 36(2): 171-183.

Yang W, Liu Y, He T et al. (2020) Spatial and temporal patterns of NPP and its response to climate change in the Qinghai-Tibet Plateau from 2000 to 2015. Journal of Natural Resources, 35(10): 2511-2527. http://dx.doi.org/10.31497/zrzyxb.20201016

Yin J, Gentine P, Zhou S et al. (2018) Large increase in global storm runoff extremes driven by climate and anthropogenic changes. Nat Commun, 9(1): 4389. http://dx.doi.org/10.1038/s41467-018-06765-2

Yin L, Dai E, Zheng D et al. (2020) What drives the vegetation dynamics in the Hengduan Mountain region, southwest China: Climate change or human activity? Ecological Indicators, 112: 106013. http://dx.doi.org/10.1016/j.ecolind.2019.106013

Yu H, Wang L, Yang R et al. (2018a) Temporal and spatial variation of precipitation in the Hengduan Mountains region in China and its relationship with elevation and latitude. $\quad$ Atmospheric $\quad$ Research, $\quad$ 213: http://dx.doi.org/10.1016/j.atmosres.2018.05.025

Yu L, Xu Y and Zhang Y (2018b) Temporal and spatial variation of rainstorms and the impact of flood disasters due to rainstorm in China in the past 25 years. Torrential Rain and $\quad$ Disasters $\quad$ 37(1): 67-72. http://dx.doi.org/10.3969/j.issn.1004-9045.2018.01.009

Yuan X, Liu Y, Huang Y et al. (2017) An approach to quality validation of large-scale 

Hazards, 89(2): 693-704. http://dx.doi.org/10.1007/s11069-017-2986-0

Yue Q, Zhang L, Liu C et al. (2016) Sensitivity of flood disaster to land use types in upstream of Ganjiang Rvier. Bulletin of soil and water conservation, 36(4): 16-21.

Zhang G, Cui P, Jin W et al. (2021a) Changes in hydrological behaviours triggered by earthquake disturbance in a mountainous watershed. Sci Total Environ, 760: 143349. http://dx.doi.org/10.1016/j.scitotenv.2020.143349

Zhang G, Cui P, Yin Y et al. (2019a) Real-time monitoring and estimation of the discharge of flash floods in a steep mountain catchment. Hydrological Processes, 33(25): 3195-3212. http://dx.doi.org/10.1002/hyp.13551

Zhang K, Pan S, Cao L et al. (2014) Spatial distribution and temporal trends in precipitation extremes over the Hengduan Mountains region, China, from 1961 to 2012. Quaternary $\quad$ International, 346-356. http://dx.doi.org/10.1016/j.quaint.2014.04.050

Zhang L, Nan Z, Yu W et al. (2018) Comparison of baseline period choices for separating climate and land use/land cover change impacts on watershed hydrology using distributed hydrological models. Sci Total Environ, 622-623: 1016-1028. http://dx.doi.org/10.1016/j.scitotenv.2017.12.055

Zhang Y, Wang Y, Chen Y et al. (2019b) Assessment of future flash flood inundations in coastal regions under climate change scenarios-A case study of Hadahe River basin in northeastern China. Sci Total Environ, 693: 133550. http://dx.doi.org/10.1016/j.scitotenv.2019.07.356 
697 Zhang Y, Wang Y, Chen Y et al. (2021b) Projection of changes in flash flood 698 occurrence under climate change at tourist attractions. Journal of Hydrology, 595: 699 126039. http://dx.doi.org/10.1016/j.jhydrol.2021.126039

700 Zhou C, Cen S, Li Y et al. (2011) Precipitation Variation and Its Impacts in Sichuan in 701 the Last 50 Years. Acta Geographica Sinica, 66(5): 619-630. 


\section{Figures}

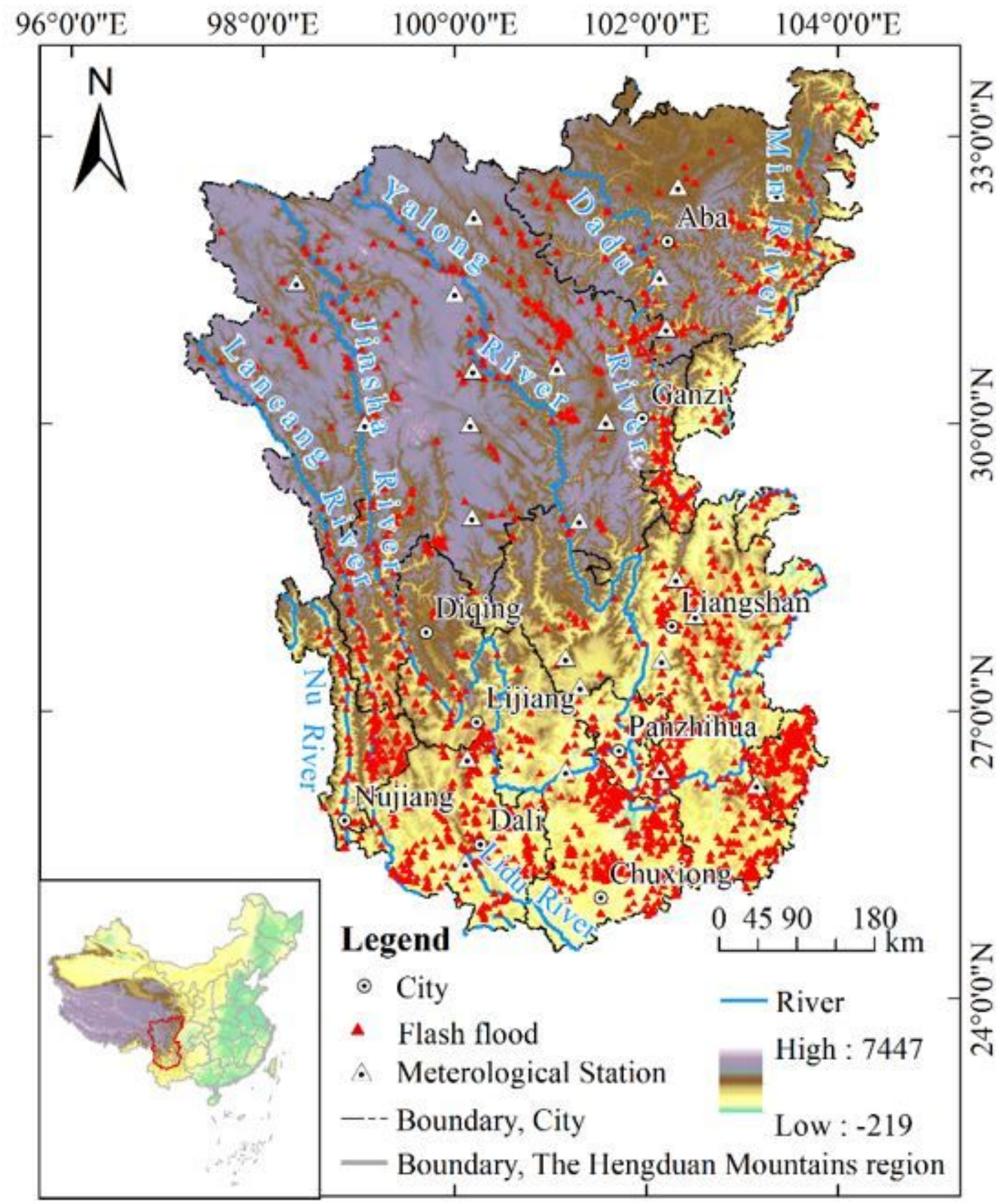

\section{Figure 1}

The HMR with meteorological stations and locations of flash flood events Note: The designations employed and the presentation of the material on this map do not imply the expression of any opinion whatsoever on the part of Research Square concerning the legal status of any country, territory, city or area or of its authorities, or concerning the delimitation of its frontiers or boundaries. This map has been provided by the authors. 

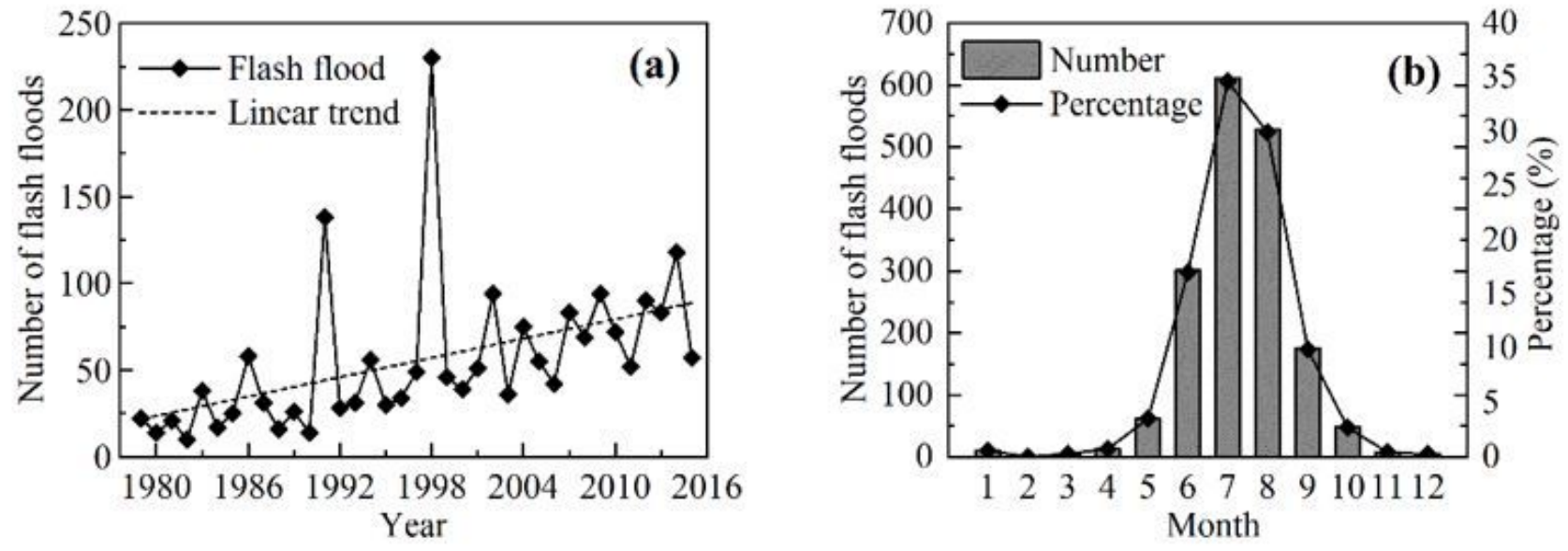

Figure 2

The statistically annual variation (a) and monthly distribution (b) of flash floods in the HMR during 19792015


Figure 3

Distribution of time frequencies on the real part of wavelet transform (a) and the wavelet variances (b) in flash floods in the HMR during 1979-2015 Note: The designations employed and the presentation of the material on this map do not imply the expression of any opinion whatsoever on the part of Research Square concerning the legal status of any country, territory, city or area or of its authorities, or concerning the delimitation of its frontiers or boundaries. This map has been provided by the authors. 


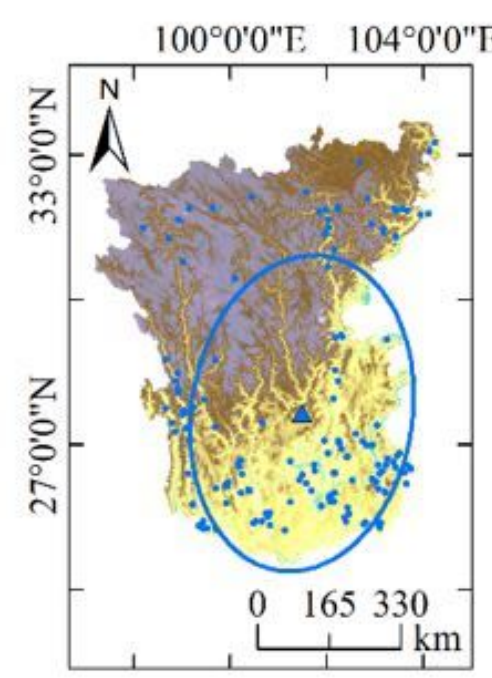

(a) $1979-1985$

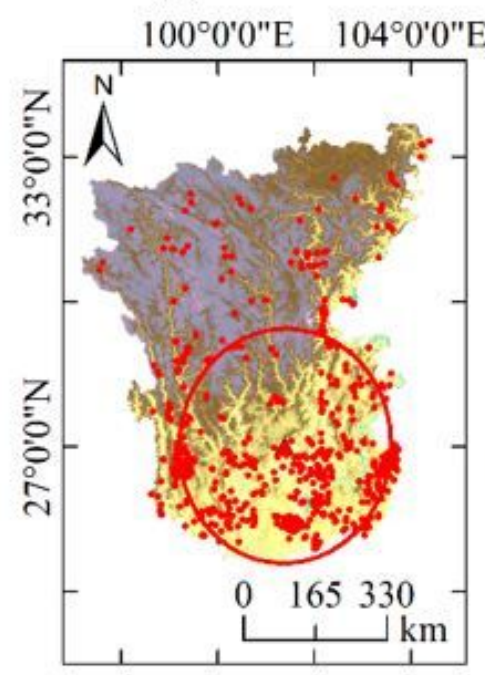

(c) 1996-2005

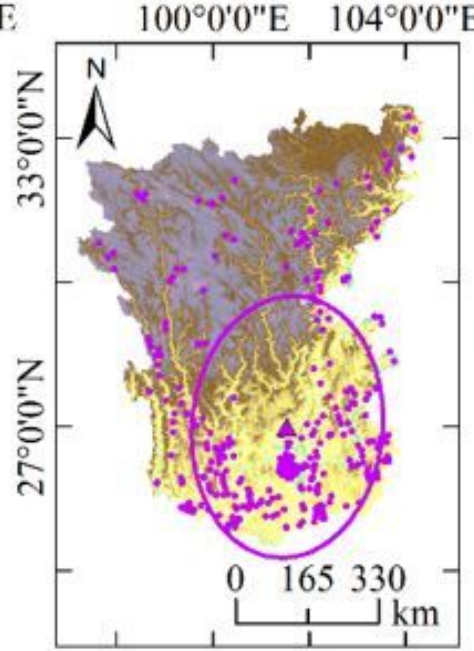

(b) 1986-1995

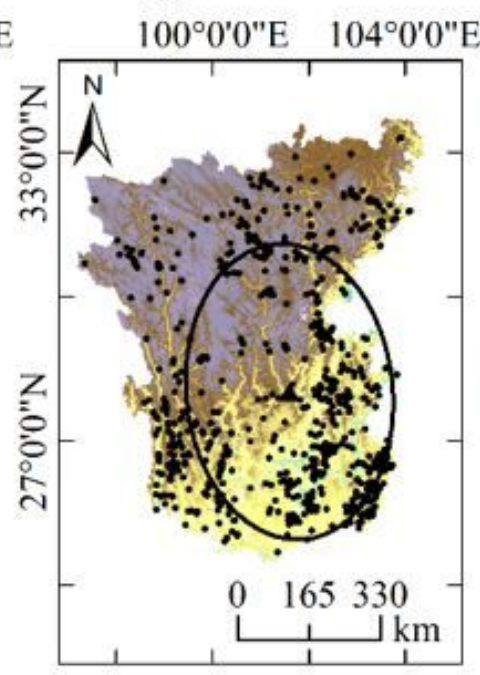

(d) 2006-2015

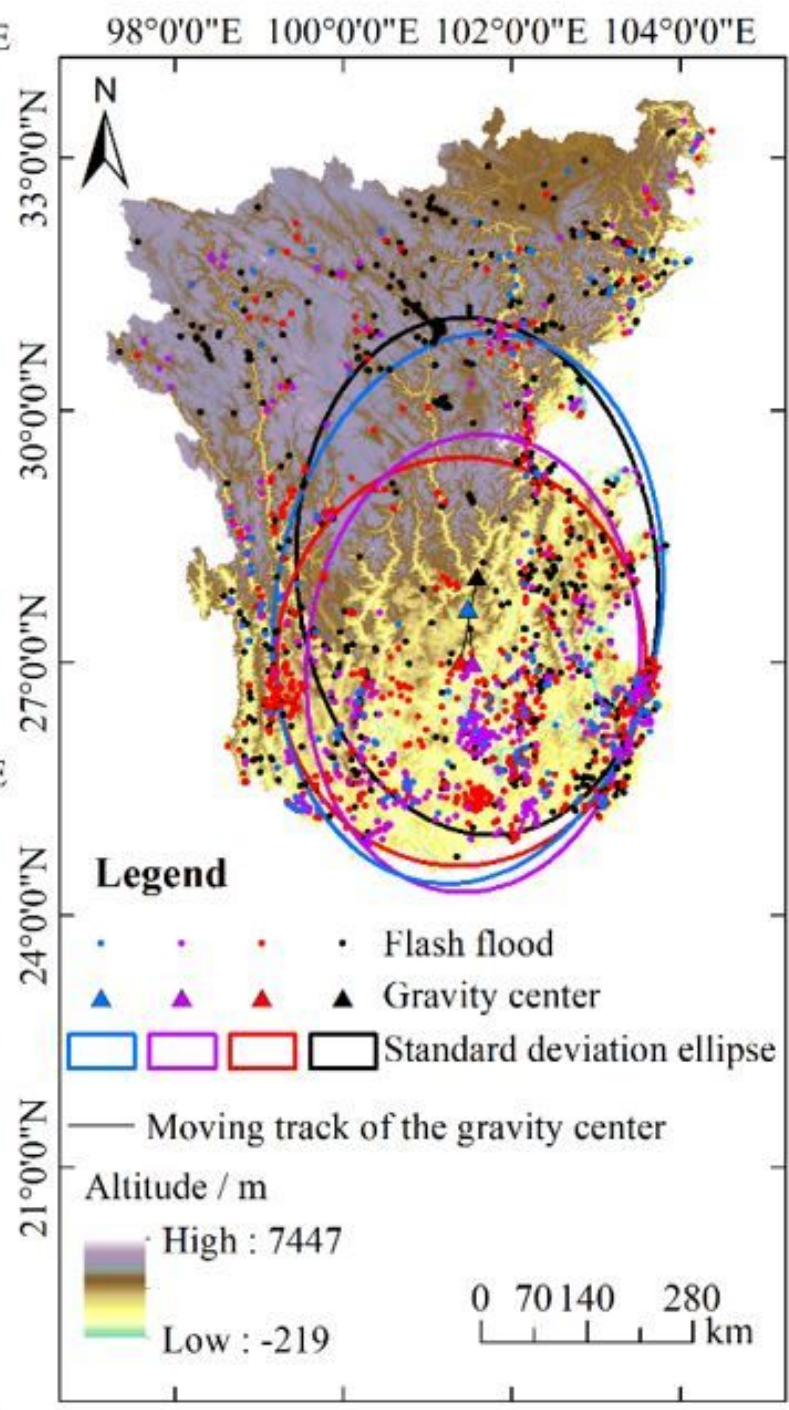

(e) From 1979 to 2015

\section{Figure 4}

Gravity Center and Directional Distribution of flash floods from 1979 to 2015 Note: The designations employed and the presentation of the material on this map do not imply the expression of any opinion whatsoever on the part of Research Square concerning the legal status of any country, territory, city or area or of its authorities, or concerning the delimitation of its frontiers or boundaries. This map has been provided by the authors. 

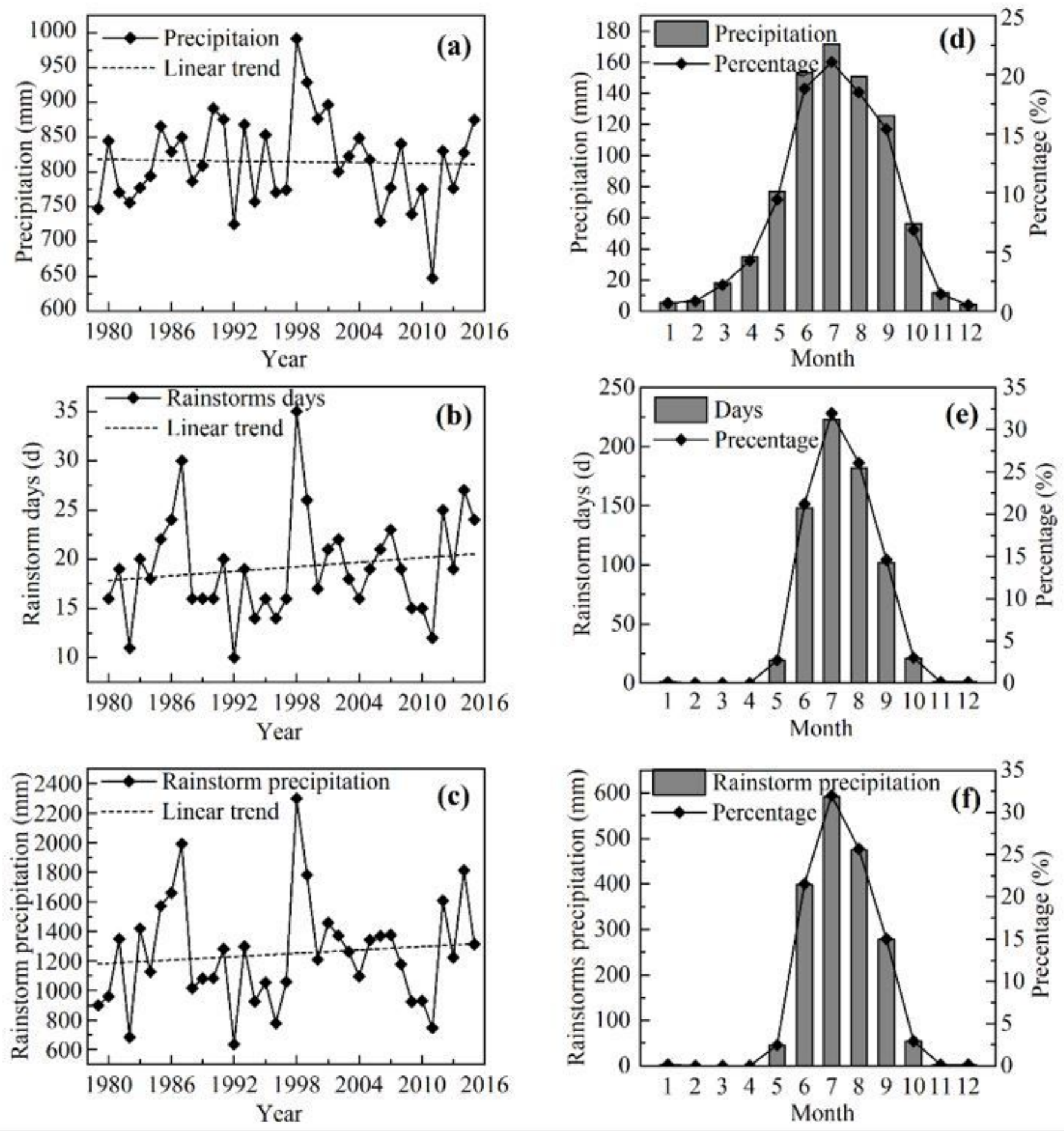

Figure 5

Annual evolution ( $a, b, c)$ and monthly distribution ( $d, e, f)$ of the rainfall (unit: $\mathrm{mm}$ ), the rainstorm days (unit: d), and the rainstorms precipitation (unit: mm) in the HMR from 1979 to 2015. 



\section{Figure 6}

Distribution of time frequencies on the real part of wavelet transform (a) and the wavelet variances (b) in precipitations in the HMR during 1979-2015 Note: The designations employed and the presentation of the material on this map do not imply the expression of any opinion whatsoever on the part of Research Square concerning the legal status of any country, territory, city or area or of its authorities, or concerning the delimitation of its frontiers or boundaries. This map has been provided by the authors. 

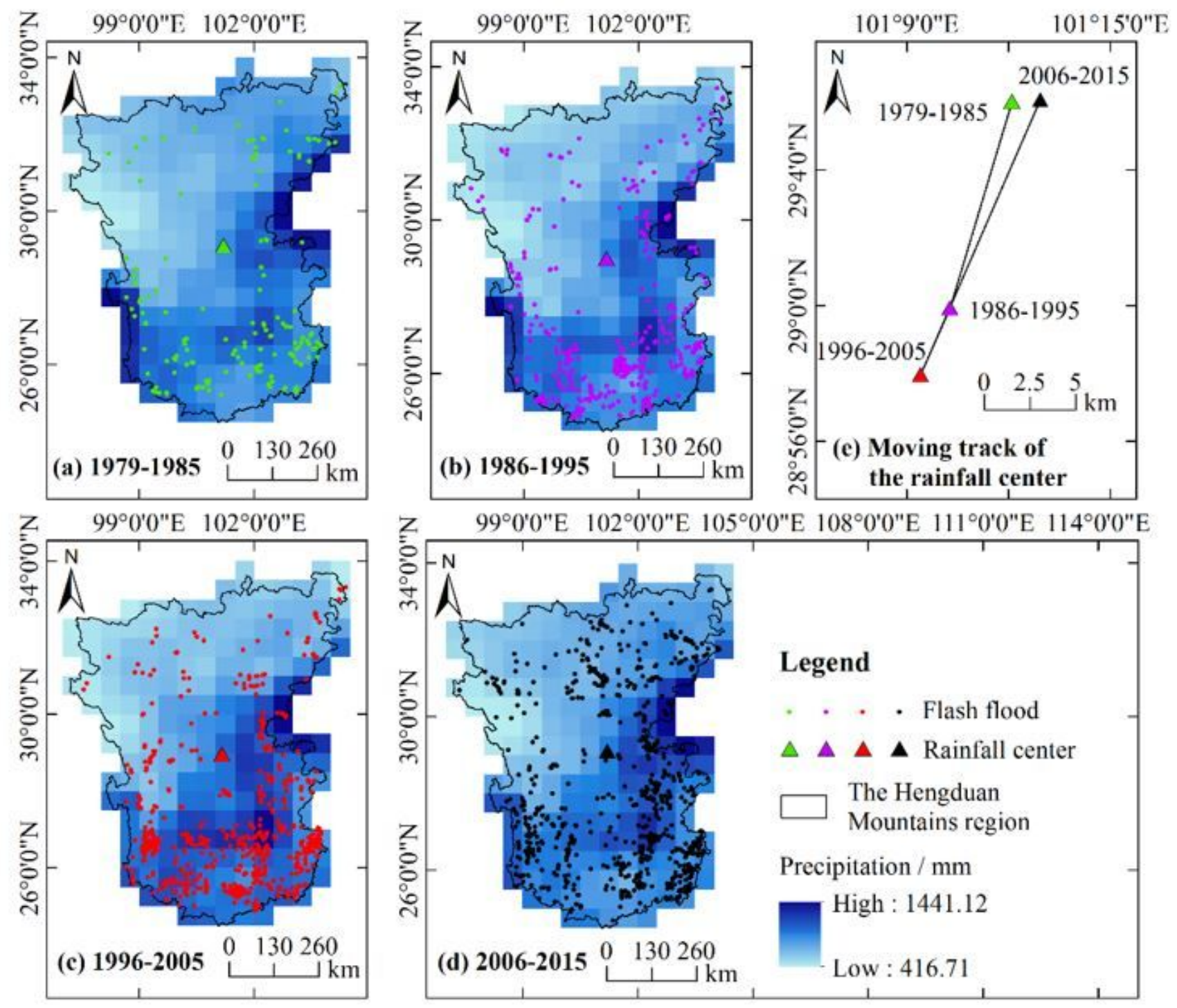

\section{Figure 7}

Moving track of the rainfall center (1979-2015) Note: The designations employed and the presentation of the material on this map do not imply the expression of any opinion whatsoever on the part of Research Square concerning the legal status of any country, territory, city or area or of its authorities, or concerning the delimitation of its frontiers or boundaries. This map has been provided by the authors. 




Figure 8

Distribution of the rainstorm days and rainstorm precipitation in meteorological stations in the HMR (1979-2015) Note: The designations employed and the presentation of the material on this map do not imply the expression of any opinion whatsoever on the part of Research Square concerning the legal status of any country, territory, city or area or of its authorities, or concerning the delimitation of its frontiers or boundaries. This map has been provided by the authors. 


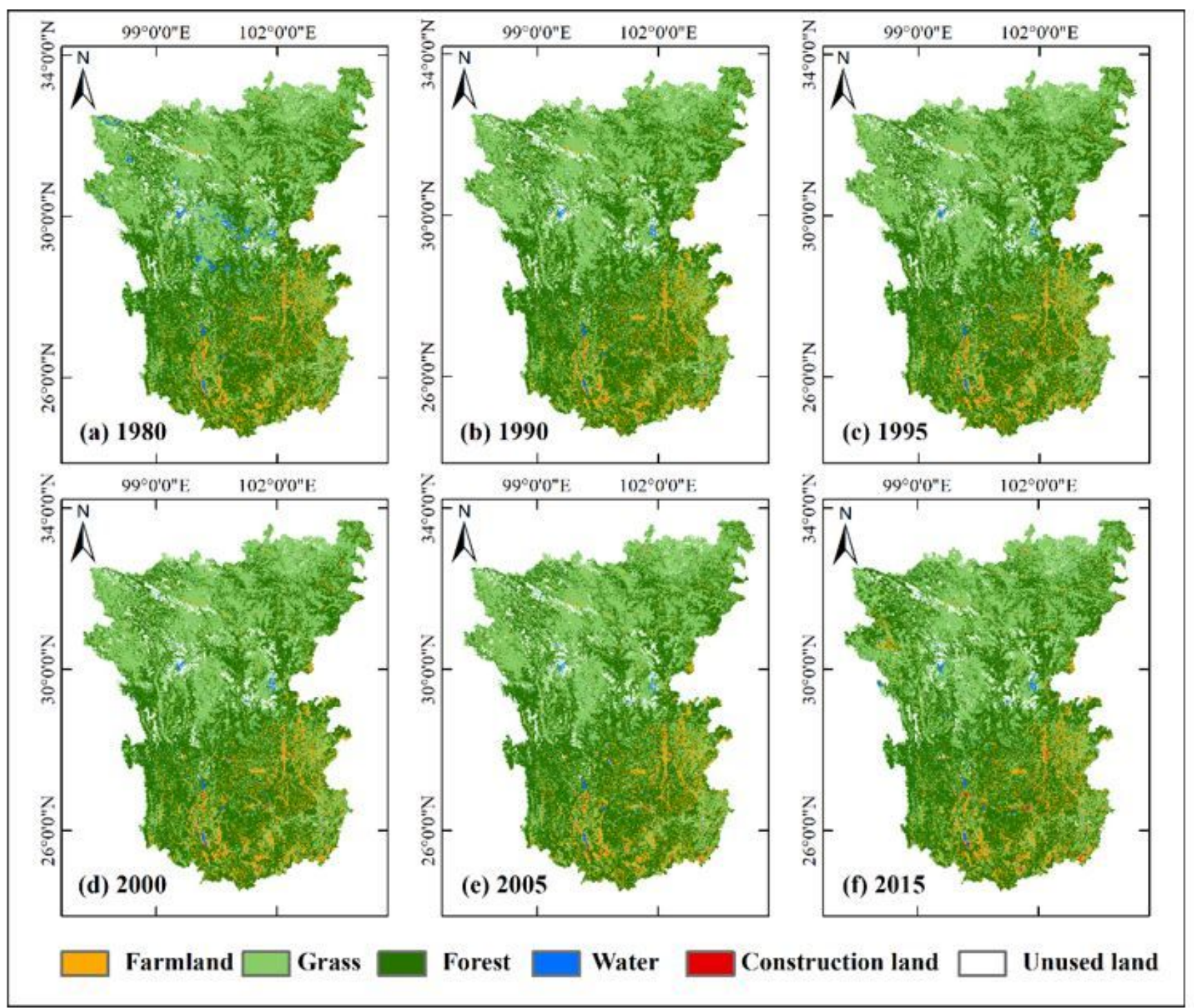

Figure 9

The land-use maps in the HMR from 1980 to 2015 (km2) Note: The designations employed and the presentation of the material on this map do not imply the expression of any opinion whatsoever on the part of Research Square concerning the legal status of any country, territory, city or area or of its authorities, or concerning the delimitation of its frontiers or boundaries. This map has been provided by the authors. 


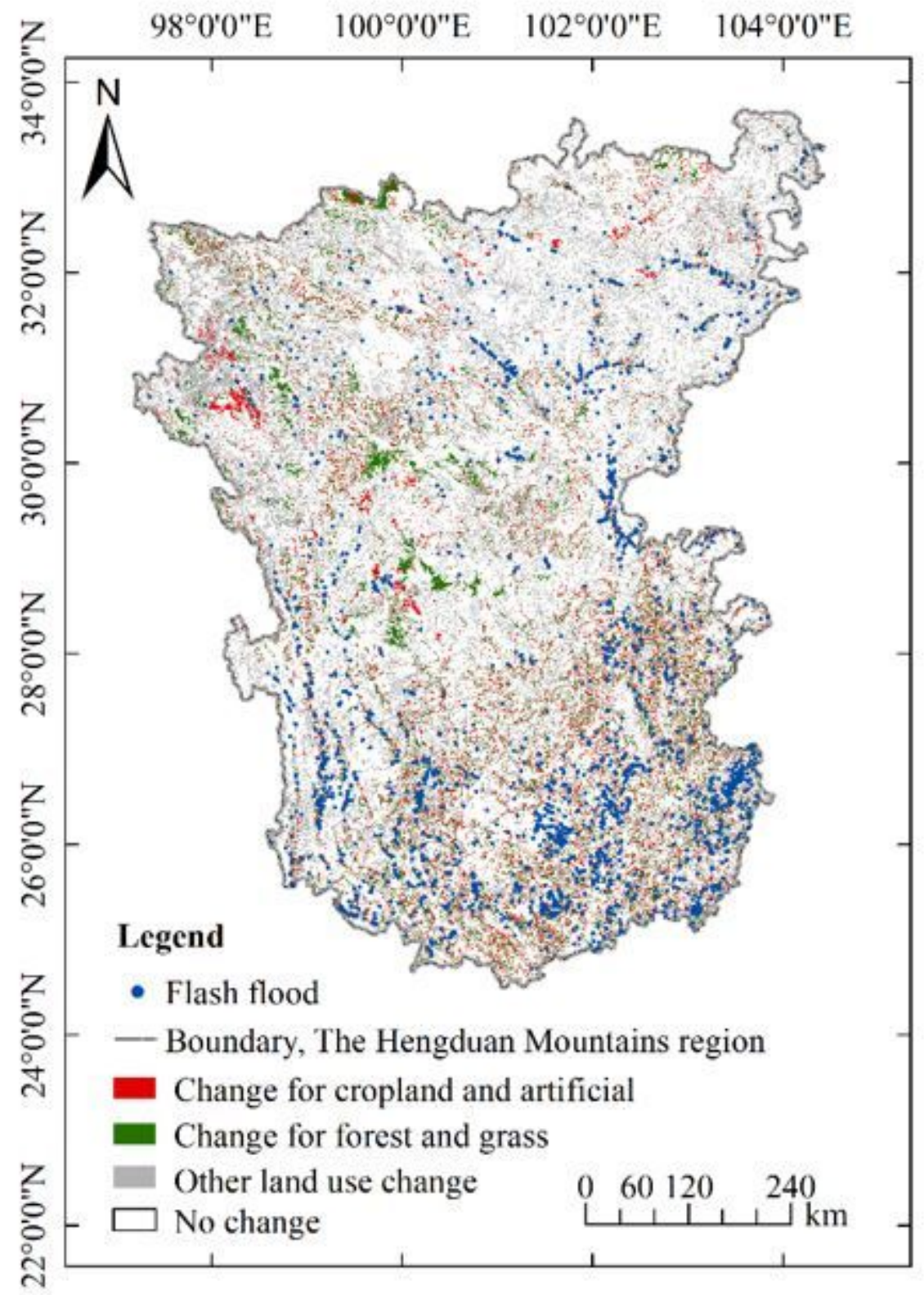

Figure 10

Distribution of land-use transfer from 1980 to 2015 Note: The designations employed and the presentation of the material on this map do not imply the expression of any opinion whatsoever on the part of Research Square concerning the legal status of any country, territory, city or area or of its authorities, or concerning the delimitation of its frontiers or boundaries. This map has been provided by the authors. 




Figure 11

Number of flash floods under different rainfall grades 